\title{
Teaching Discussion Skills As Part Of Further Teachers' Training
}

\author{
E. Yu. Malushko \\ Department of English Philology \\ FSAEI HI "Volgograd State University" \\ Volgograd, Russia \\ e.malushko@volsu.ru
}

\author{
O. A. Maletina \\ Department of Foreign Languages for Specific Purpose \\ FSAEI HI "Volgograd State University" \\ Volgograd, Russia \\ o.maletina@volsu.ru
}

\author{
V. A. Tsybanyova \\ Department of Foreign Languages and Teaching Methodology \\ SAEI FPE "Volgograd state academy of Postgraduate Studies" \\ Volgograd, Russia \\ walenday14@yahoo.com
}

\begin{abstract}
Development of the educational establishments in Russia, evolution of the teacher's professional standards and integration of the national educational system into European academic space influence all educational participants dramatically. Students have to demonstrate their competitiveness, creativity, mobility, develop and attract their critical thinking and coordinate with the rest of the class and the teachers. As for teachers, their professional standards are being paid a lot of attention nowadays and are still being worked out to reflect and meet the needs of the local and international labour market. To achieve this goal, the authors consider further teacher training courses as an effective mass way to promote active teaching and increase teaching competences. This article considers forms of organizing teacher's professional development, types of training courses, discussion, questioning activities and techniques to prolong the discussion. The authors also define the qualities of discussion participants that are demanded by the lecturers. The selection of educational resources is also given a great deal of attention as an important issue of arranging a discussion.
\end{abstract}

Keywords-discussion skills, further teachers' training, infocommunication and interaction technologies, professional success, academic discussion, educational discussion.

\section{INTRODUCTION}

Due to intensifying Russia's integration into the European and world space, the educational system has to be modernized because strategic tasks of national and international economic and social development require hiring new specialists who demonstrate high qualification and deep knowledge of the latest technologies. Modernization of the educational system leads to increasing teacher's professional qualification, improving pedagogical culture and professional competence under the conditions of modern life [1]. Changes in the system of further education are aimed at creative, initiative, mobile personality; therefore, there is a necessity of a new approach to teaching educational specialists.
Great changes in different spheres of Russian society enable changes in the educational system resulting in its further development and transformation of its core features. In the framework of the key legal papers regulating the system of national education such as the Russian Federation National doctrine of Education till 2025 and the State programme of education development in the Russian Federation for 20132020, the Strategy of long-term social and economic development in the Russian Federation till 2020 highlights vibrancy and particular consistency in development of economic and social sphere [2]. In these spheres there is the increasing need in competitive, qualified and efficient staff, especially teachers, who can successfully solve tasks of the innovative development; that is why it is important to find proficient teachers and apply new methods of teachers' training [3]. According to the Federal State Educational Standards of General Education and Teacher's qualification standard, school teachers should achieve certain professional level called category (zero, first, higher) and continuously improve their skills with the help of further educational programmes which usually last 72 hours every 5 years. As for higher educational (HE) institutions, there is no pursuit of categories, but the level of HE teacher's qualification should correspond to the position requirements that cover different aspects of academic, research, publication and social activity of university staff.

Thus the conditions for cooperation and mutually beneficial activity of schools should be created to provide opportunities for finding new qualified and experienced teachers, methodical support, counseling in realizing this Federal Standard, integrating innovative experience of other schools, monitoring and researching educational results and the effectiveness of applied innovations.

New standards require deep understanding of the essence of such technologies as person-oriented and problem teaching, project and research activities, infocommunication and 
interaction technologies [4]. The Federal State Educational Standard is aimed at altering the content and forms of organizing methodical guidance at schools, shifting to inside further training. Meanwhile, there are some contradictions between the necessity to solve current innovative tasks under the conditions of economy modernization and deficiency in applying innovative forms of teaching at schools, further teachers' training; the necessity to create efficient environment for integrating these solutions and reluctance of administrative and managing staff to realize the given changes. The changing content of the teaching activity under the Federal State Educational Standard is oriented to teaching the theory and practice of the pedagogical projecting, creating assessment means and using digital educational resources [5].

Therefore the standard requires the dramatic change of the content and form of internal educating teachers at school and their further professional development [6].

\section{FORMS OF FURTHER TEACHERS' TRAINING}

The process of personnel certification includes periodical confirmation of the teacher's qualification, which means that teachers can perform school tasks and develop their professional competence in the field of foreign language teaching. Under the programme of the national initiative 'Our new school', teachers should be open to everything new, understand children's psychology and peculiarities of their development, possess proficient subject knowledge and skills. The main tasks of a teacher are to help pupils to choose their future specialty, to teach them to be independent, to encourage their creative initiatives, to develop their confidence. Teachers need to be understanding, attentive and sensitive to pupils' interests, open to new opportunities. Accordingly, the role of a director will also change because the level of his/her freedom and responsibility will increase [3].

Nowadays the conditions of professional activity of foreign language teachers contribute badly their selfrealization and interrupt their professional success because teachers have quite little time to study methodical literature, to attend colleagues' lessons and to analyse their own teaching methods. The described changes result in improved requirements for teachers' qualification which pay great attention to professional pedagogical competences [7].

Teachers' further training is a discontinuous process concerning renewal of professional knowledge and skills since the professional teacher's competence is the basis of the educational system of any democratic state. Modern forms of organizing teachers' further education should stimulate teacher's development and satisfy society's need in qualified teaching staff. That is why the new format of pedagogical meetings and seminars concerning urgent educational problems, pedagogical recommendations, educational and didactic materials leads to the realization of the most important task in the further professional training of foreign language teachers [8].

Nowadays there are many forms of teachers' further training that depend on the type of participation:
1) face-to face training, for example studying in a group or following the individual educational plan (case studies, thematic innovative courses, methodic seminars, practical work, contests of pedagogical skills, open lessons, conferences);

2) distance or remote training supposing individual or group study with the help of computer and Internet technologies (participation in on-line forums, distance courses, professional webinars, Skype-conferences).

According to the length of the course, we can distinguish the following types:

1) Short programmes (lasting less than 72 hours) cover studying issues in professional subject spheres. Completing this course, each participant prepares a paper and then defends it or passes the exam. The successful passing an exam leads to getting a certificate which confirms completion a course.

2) Long programmes (lasting more than 108 hours, often more than 300) cover studying actual issues and innovations more deeply in professional subject spheres. After completing the course, participants pass exams, get credits, defend their papers and as a result get certificates confirming further training and acquired qualification.

3) Seminar courses (lasting more than 72 hours and less than 108 hours) cover studying different aspects in the scientific sphere. Participants also pass exams or defend their papers. If they pass exams successfully, they will get personal certificates confirming their further training and acquired knowledge.

To solve tasks of forming professional competences among teachers of foreign languages, one needs a new approach to organize the process of teachers' further education; that is why it is necessary to consider in-class teaching courses [9]. As for in-class activities, educational content should be improved (subject information and materials stimulating further formation of the professional competence) and the material should be presented in a peculiar way. Only in this case students can fully understand practical material, and the educational process is aimed at developing cognitive activity, forming professional style of thinking and readiness to self-study.

Course training based on democratic and humanistic principles, different methods and technologies, and namely discussions creates the experience of joint activity, thus the interaction of teachers is defined by peculiarities of their joint practical activity.

The achievement of a good result in the process of discussion requires coordination of main parameters, which leads to the constructive management of activity [6].

\section{TEACHING Discussion SKILlS AS A PART OF FURTHER TEACHERS' TRAINING}

Discussion is a communicative process of information change when there is an interaction of at least two participants with definite communicative intentions since the text generation happens is a definite aim and intention depending 
on what one are going to say and who one is going to speak to [10]. Consequently, teaching communication is connected with forming skills to organize speech interaction, achieve the communicative aim and realize definite communicative intentions.

Thus academic discussion at seminars helps to develop and improve critical thinking, form communicative and discussion culture.

Academic discussion is a form of cooperation which is used to study two or several points of view of a problem to find the truth (the right point of view). It means that participants should share their ideas, opinions and judgments to find the truth and each of them takes own part. The aims of discussion classes are to develop spontaneous creative speech (combining communicative, interactive and perceptive features) and critical thinking. The strategy and methods should aim at turning academic situation into the real communicative one [11]. The usage of group discussions at classes will contribute to more effective studying the material because teachers will not just be provided with the material and knowledge, but they will have to obtain the material and acquire knowledge themselves by solving tasks. The main feature of academic discussion is a dialogue position of a tutor who creates special environment for discussions, sets the discussion rules and asks the participants to follow definite rules [12].

According to M.V. Clarin, there are the following features of the educational discussion:

- $\quad$ work and cooperation of the group which includes facilitators and participants;

- organization of corresponding discussion place and time;

- interaction including speaking, listening, nonverbal means of expression;

- orientation to the achievement of educational aims [13].

Teachers as course listeners should be divided into groups of four or five people to work together on the problem. Such division will contribute to their understanding of the importance of the students' participation in the discussion. Communication during the discussion stimulates students to find different ways of expressing their ideas and be open to new opinions, which is realized through educational material and communication during the discussion [14].

Teachers should be given the theoretical material concerning parts of the educational discussion and the speakers: theme, speech stimulus, key words and speech reaction, setting questions [15]. Let us consider that discussion theme includes aspects concerning the urgent problem. A stimulus generates a speech reaction if the problem is actual and interesting; questions should be set to control the process of discussion (teachers need to be taught how to prepare right questions and stimulate students to express their opinions more actively). Key words are aimed at helping students to generate their thoughts; a speech reaction contains monologues of some students, students' and teacher's statements.

Basing on some principles, it is possible to distinguish the following kinds of discussion: 1) thematic (study of the definite topic) and non-thematic (without dependence on the theme, text and material being studied at the moment); 2) prepared and spontaneous (with the use of the printed text or illustrations, pictures, plans, schemes etc.) [17]. The educational process requires conducting organized discussions which are devoted to definite themes and have limited time.

It is necessary to explain the tasks of the educational discussion to teachers, therefore they should know that the educational discussion is aimed at realizing two groups of the tasks: 1) content tasks which are oriented to achieve students' understanding of contradictions and difficulties connected with the discussed problem and their readiness and ability to think creatively and to use their knowledge; 2) organization tasks which are connected with assigning roles, following the definite rules.

There are different kinds of discussion which can be used by teachers during their lessons:

- $\quad$ round table is the discussion engaging several small groups of about 5 students who try to share their opinions within their group and with the rest of the class;

- panel discussion is the discussion engaging an expert group of 4-6 participants and one of them is elected as a chairman or facilitator; this group works out their reasons or ideas first and then present them to the rest of the class;

- forum represents the discussion similar to panel discussion but the expert group actively communicates and exchanges opinions with the rest of the class;

- workshop is the discussion when the participants present their reports with different points of view and then answer the questions of the class;

- debate is the formalized discussion on the basis of the participants' reports from two opposing groups with a persuasive aim, for example parliament debate or debate at court;

- role play is the discussion according to the definite pre-set task or role.

Thus teachers should understand that the success of teaching a foreign language depends on the definite aim of the education and under the interaction approach. It means that students interact successfully with the help of a foreign language. Let us consider some exercises which are oriented to teaching discussion skills.

ACTIVITY 1. Group the phrases given below according to the discussion stages they signal.

Stages of a discussion: opening, keynote speech, main discussion, summary, closing. 
Signals: I would say that...; On the one hand...; On the other hand...; There are many benefits to...; One of the drawbacks of .. is ...; My personal opinion is that...; Shall we get started? Could I come at that point? Let's finish there; I'd like you to start, John, with... Let me sum up... The main aim of this discussion is... Thanks for a useful discussion... OK. Let's start; Right. We have decided then to...; I am not sure I agree with that because ...; It's a good idea but ...; Do you agree with me that ...; Some people might not be too keen on that because...

This exercise will help to teach students to structure their discussion with the help of the useful phrases and understand the role of the participants during the discussion.

ACTIVITY 2. Complete the table with the words and phrases given below. Remember that they signal different stages of a discussion and can be used by the chairperson only, by the participants only or by both. Decide what stage of the discussion they signal and who can use them: a chairperson, participants or both.

\begin{tabular}{|c|l|}
\hline Chairperson & \\
\hline Participants & \\
\hline Both & \\
\hline
\end{tabular}

Words and phrases. You might be right, actually; I've got a point; As far as I'm concerned ...; In my opinion ...; I believe ...; Let's face it, ...; I think we should first of all look at... Just a minute! I would like to begin by... I wonder if I might comment on that last point. I agree up to a point, but... On the whole...; It's a bit difficult to decide; I think it depends ...; I think you're right ...; I don't really agree with that because ..., I'm not really sure this ...

This exercise helps to decode intentions of the discussion participants orienting to speech signals.

ACTIVITY 3. Match each intention with the corresponding part of the discussion. Some intentions have been marked as examples.

\section{Speaker's intentions \\ Disagrees. \\ Asks for an opinion. \\ Expands his point of view.(2) \\ Gives an opinion.(2) [16]}

Teachers should be involved into the educational discussion in order to understand that the discussion should be based on the arguments, because arguments are used by students to prove their point of view when they defend their position. The skill of proving one's point of view is the main feature of the effective educational discussion [9]. There are three stages of discussion: 1) preparatory: teachers should choose theme, form, define time limit, arrange learning environment, find necessary materials, assign roles to the participants; 2) discussion of a problem; 3) conclusion, analysis of discussion.

During the discussion, teachers as course listeners will be taught how to cooperate within the group and will understand how to teach their children to be interactive and tolerant. And, of course, the success of the discussion depends on the discipline, communicative skills and the level of knowledge. Students should respect other peoples' opinions, follow the stages and the rules of the discussion, be tolerant to other points of view.

Discussions could be used in the following situations:

$>$ teachers of foreign languages work with resources with different points of view on a problem;

$>$ a practical problem with several solutions (with results) is being discussed;

$>$ teachers are divided into groups according to ways of solving problems in the process of a discussion.

Zair-Bek S. considers that one should remember definite rules: in discussion the specific psychological factor is the communication of partners who share the same information when the lector is the partner who knows more. When partners have the same information it increases their intellectual opportunities and reduces barriers of communication and increases its productivity [17].

Scientists considering teaching writing and reading with the help of critical thinking suppose that, on the one hand, productive discussion is the result of good critical thinking among its participants, and, on the other hand, the discussion is the instrument of developing critical thinking.

Thus, the peculiar feature of organizing a discussion under the technology of critical thinking development through writing and reading is thinking about the text one has read. Therefore, some scientists note that the main condition of the material understanding is the so-called 'subjective criticism' including sense stress and interpretation of the text. As a result of the text work and considering its aspects, there is a community where members share their impressions which lead to the deep understanding of the text and allow people to know each other better.

As is well known during the discussion, there appears a possibility of changing the dialogue into a dispute and the decrease of participants' activity. Dillon G.T. defines four steps or techniques which can be used by lectors to continue a discussion.

1. Affirmation. It is a way to react, confirm understanding or express perplexity about what has been said. Affirmative phrases are less tough than questions, and therefore they motivate a freer response. A lecturer can say, 'As I understand you are saying...', or 'It has just reminded me what has been said earlier'.

2. Questions. Participants of the discussion will ask, answer and discuss their questions more enthusiastically, that is why it is better to motivate teachers to answer these questions and provoke discussion.

3. Signals. As lecturer's comments are often more authoritative, it is thought to be better to manage the discussion with the help of gestures and signals without saying anything. Puzzled look, expression of approved interest, raising a hand can become such signals. 
4. Keeping silence. When the question is asked, the students or participants of discussion should be given enough time to think it over, but of course not too long, as there are some pre-set time limits and rules.

One should notice that the positive result of the discussion is the solution of the problem. In fact, the important characteristic of effectiveness is achievement of the discussion aim and obtaining the desired result which is defined as a standard by the lecturer. The educational problem can be solved in the science, but the discussion participants are looking for a solution over again.

Clarin M.V. considers that the important aim of discussion includes improving communicative skills of foreign language teachers. When there is a variety of opinions, group discussion and problem solution facilitate forming the following:

- deep and sustainable knowledge;

- $\quad$ skills to cooperate within the group when preparing and adducing arguments;

- $\quad$ skills to share arguments taking into consideration that they can coincide with the individual point of view or differ from it;

- respect for the discussion participants and their judgments [13].

\section{CONCLUSION}

Thus educational discussion when training foreign language teachers is important not only from the point of solving content and subject tasks, but also as the process because teachers have the opportunity to monitor the development of their own thoughts and capabilities to business and cultural interaction.

As the authors have already mentioned, there are different kinds and models of discussion in the scientific literature: problem discussions, discussions with game modeling, debates and disputes. According to D. Halpern, different strategies and ways of discussion help to develop the following qualities:

1. Readiness to plan (it is important to organise thoughts, to expound a conception consequently).

2. Flexibility (readiness to perceive ideas of other people, being a generator of one's own ideas and thoughts).

3. Persistence (solution of difficult tasks without slowdown).

4. Readiness to correct one's own mistakes (skills not to justify one's wrong decisions, but to come to right conclusions).

5. Awareness (skills to observe oneself during the thinking process, to follow arguments).

6. Search of compromise decisions (it is important when decisions are perceived by other people and are not left at the level of statements) [18].

There is one more serious problem concerning finding materials especially educational texts (for seminar). On the one hand, one should consider that educational texts coincide with the topics which are studied at schools. On the other hand, these texts containing an element of novelty which should not be familiar to seminar participants.

Texts found by professors and texts created by seminar participants can become sources of information. Moreover, participants' questions can create the basis for the training course. A great deal of questions means that participants are interested, ready to analyse the information and to think it over creatively. Therefore, the lecturer has to stimulate asking questions even though some of them will seem critical and complicated and will alter the class. According to Mariko V. and Shvets I., participants' questions can be divided into several categories:

1. Factual questions are asked by people who are curious and would like to know some aspects of the new material.

2. Specifying questions are indicators for a professor because they help to correct explanations and instructions which were not understood.

3. Research questions are connected with the analysis of the seminar process and mental transfer of models and strategies into the class.

4. Modeling questions (for example, if one tries to use something at this stage of work...? Could pupils do the offered task with this strategy?).

It is necessary to leave time for such questions during the discussion and it is better to use practical materials (lesson plans, video lessons, articles describing similar experience, pupils' papers) trying to find answers.

5. Critical questions are asked to puzzle the professor. Participants who ask such questions are eager to show that they know the subject or they have critical attitude to the offered decisions on different reasons. But sometimes people try to puzzle because they have doubts (for example: 'Are you sure that pupils will have enough time to read such a long text and therefore the strategy will work?'). The most successful answers to such questions can be found in the concrete practical experience of the professor and other teachers. These questions are essential for participants because they show the real problem and teachers can look for its solutions during educational seminars and experimental pedagogical practice. It is necessary to pay attention to such questions. They can be used during the seminar concerning lesson planning or demonstration of the video fragment of the lesson [19].

Thus, it is necessary to note that the competence approach implies the specificity and essence of organizing the process of teachers' training changes [20]. Discussion is one of the actual forms of the teachers' training course. Lecturers and participants have to devote much time and efforts to organize the discussion. Discussions allow one to use all skills and as a result there are formed discussion and communicative competences (here: foreign communicative competence), satisfaction of the mutual productive activity. 


\section{References}

[1] A. Dolzhikova, V. Kurilenko, Yu. Biryukova, "Integrative teaching model of reading as a component of translator's professional activity" In: "3rd international multidisciplinary scientific conference on social sciences \& arts SGEM 2016: conference proceedings," Book 3, vol. 1, 2016. pp. 553-562.

[2] N. Shamne, A. Petrova, L. Rebrina, M. Milovanova, "Phenomenon of Memory and Category of Space: Gnoseological and Communicative Status" XLinguae. EuropeanScientificLanguageJournal, vol. 7. Iss. 3 (June). pp. 32-49, 2014.

[3] M.A. Suzdalova, V.G. Lizunkov, E.Yu. Malushko, N.A. Sytina, V.E. Medvedev, "Innovative Forms of Partnership in Development and Implementation of University-Business Cooperation," The European Proceedings of Social \& Behavioural Sciences EpSBS, vol. XIX, Article \#61, pp. 450-455, 2017.

[4] E. Malushko, O. Maletina, V. Lizunkov, V. Tsybaneva, "Use of virtual learning system for educating students with disabilities and special needs," 3nd international multidisciplinary scientific conference on social sciences \& arts SGEM 2016: conference proceedings, Book 1, vol. 1, pp. 481-487, 2016.

[5] N. Pomortseva, V. Kurilenko, Yu. Biryukova, V. Sinyachkin, M.Makarova, "Integrative didactic model of linguacultural adaptation of foreign students at an international university," Book 1. Vol.1, pp.845853, 2016.

[6] S. A. Korolkov, A. G. Losev, I. M. Reshetnikova, V. V. Tarakanov, "Budgeting Model of Structural Units Based on Normative Per Capita Funding," European researcher, No. 31 (70), pp. 498-508, 2014.

[7] V. Lizunkov, V. Marchuk, E. Podzorova, "Identification of Criteria, Features and Levels of Economic and Managerial Competencies Development for Bachelors in Mechanical Engineering," Procedia Social and Behavioral Sciences, vol. 206. pp. 388-393, 2015.

[8] Yu.N. Kulichenko, O.Yu. Popova., Yu.I. Linkova, "The use of multimedia presentations in teaching a foreign language to students of non-llanguage specializations," The world of science, culture, education, No. 4 (59), pp. 30-33, 2016.

[9] M. Loschilova, V. Lizunkov, A. Zavyalova, "Professional Training of Bachelors in Mechanical Engineering, Based on Networking Resources," Procedia - Social and Behavioral Sciences," vol. 206. pp. 399-405, 2015
[10] M.R. Zheltukhina, A.V. Zinkovskaya, V.V. Katermina, N.B. Shershneva, "Dialogue as a Constituent Resource for Dramatic Discourse: Language, Person and Culture," I"nternational Journal of Environmental and Science Education," No. 11(15). pp. 7408-7420, 2016.

[11] A.V Schekoldina, "Formation of foreign-language discussion skills as a component of interactive competence among students of non-linguistic universities (on the basis of English language) " candidate's thesis in Pedagogical Science. Volgograd, 2005, $182 \mathrm{p}$.

[12] M.R. Zheltukhina, L.G.Vikulova, S.V. Mikhaylova, L.A. Borbotko, A.R. Masalimova, "Communicative Theatre Space in the Linguistic and Pragmatic Paradigm," XLinguae Journal, vol. 10, Iss. 2, pp. 85-100, 2017.

[13] M.V. Clarin, "Conceptual Challenges in Understanding Innovative Education in Organizational Context," International Journal of Cognitive Research in Science, Engineering and Education, vol. 4, No. 1. P. 79-84, 2016.

[14] E.V. Politsinsky, L.G. Demenkova, O.V. Medvedeva, "Ways of students training aimed at analytical development while solving learning tasks," Procedia - Social and Behavioral Sciences, vol. 206, pp. 383-387, 2015.

[15] V.L. Skalkin, G.A. Rubinshtein, "Speech situations as a means of developing unprepared speech," Foreign languages at school, No. 4, vol. 5, pp. 25-33, 2012.

[16] V.G. Lizunkov, M.G. Minin, E.Y. Malushko, V.E. Medvedev, "Developing economic and managerial competencies of bachelors in mechanical engineering," SHS Web of Conferences, vol. 28, 2016.

[17] M. Agranovich, S. Zair-Bek, I. Seliverstova, E. Shishmakova, "Questions addressed to V. V. Putin during an Internet conference on careers," Russian education and society, vol. 49, Iss. 12, pp. 58-68, 2007.

[18] D. Halpern, "Psychology of critical thinking", 4th ed. St. Petersburg: Peter, 2000, $512 \mathrm{p}$.

[19] S. Zair-Bek, V. Mariko, I. Shvets, "Working with Adultsm" "Thinking Classroom," vol. 7,. No.1, pp.11-19, 2006.

[20] M.A. Suzdalova, E.V. Politsinskaya, A.V. Sushko, "About the problem of professional personnel shortage in mechanical engineering industry and ways of solving," Procedia - Social and Behavioral Sciences, vol. 206, pp. 394-398, 2015. 